\title{
Androgenic and Anabolic Possibilities of Mucuna Pruriens
}

\author{
Renata Leite Tavares ${ }^{1,3}$, Maria da Conceição Rodrigues Gonçalves ${ }^{1,3}$, Jailane de Souza Aquino ${ }^{1,3}$, \\ Raquel Suelen Brito da Silva ${ }^{2,4}$, Alexandre Sérgio Silva ${ }^{2,4, *}$ \\ ${ }^{1}$ Department of Nutrition, Federal University of Paraíba, João Pessoa, Brazil \\ ${ }^{2}$ Department of Physical Education, Federal University of Paraíba, João Pessoa, Brazil \\ ${ }^{3}$ Nutritional Sciences, João Pessoa, Brazil \\ ${ }^{4}$ Physical Education, Federal University of Paraíba, João Pessoa, Brazil \\ *Corresponding author: alexandresergiosilva@yahoo.com.br
}

\begin{abstract}
Mucuna pruriens is an Indian legume composed by high amounts of proteins and carbohydrates and small concentration of lipids. It has been used ethnopharmacologically as hipoglicemic, anti-inflammatory, diuretic, hypolipidemic and mainly to Parkinson Disease treatment. Since Mucuna pruriens improves spermatogenesis, testis weight and increased the production of testosterone in rats, it has been assumed that mucuna has anabolic potential for muscle hypertrophy, so it has been commercially exploited as an ergogenic aid. This mini-review shows, in addition to promoting increased testosterone, increase in epididymal protein, thus confirming that its extracts may have influence on androgenic aspect. Despite this, it is necessary to confirm these findings in humans, since the studies analyzed were made only in animal model.
\end{abstract}

Keywords: legume, anabolism, hypertrophy, strength, exercise

Cite This Article: Renata Leite Tavares, Maria da Conceição Rodrigues Gonçalves, Jailane de Souza Aquino, Raquel Suelen Brito da Silva, and Alexandre Sérgio Silva, "Androgenic and Anabolic Possibilities of Mucuna Pruriens." Journal of Food and Nutrition Research, vol. 5, no. 12 (2017): 925-927. doi: 10.12691/jfnr-5-12-7.

\section{Introduction}

For many years, Ayuverdic medicine uses Mucuna pruriens (MP) in the treatment of Parkinson disease, because of rich composition in levodopa, similar to a largely drug used in the treatment of Parkinson [1]. Other studies have found further properties of MP using all parts of the plant (leaf, stem or pod), but the majority of the researches use its bean. These studies have been proposed it hypoglycemic effect [2], anti-inflammatory [3], hypolipidemic [4] as well as estrogenic activity [5] and androgenic [6,7] in an animal model.

Data from the latest researches are creating a speculation regarding the ergogenic activity of this bean in sports. Although there are only speculations and there is a lack of scientific evidence, products based on MP extract are being widely sold and presented in media as an herb derived nutritional supplement promising weight loss, hypertrophy and improvement in sports performance.

The goal of this review is to collect scientific evidences that prove some of therapeutic properties of this legume and to explain the speculations regarding to possible applications of MP extract for weight loss and hypertrophy proposes.

\section{Methods}

This review was formulated through literature searches using Pubmed and Higher Education Staff Improvement Commission database. The following keywords were used: "Mucuna pruriens and properties" and "Mucuna pruriens and androgenic" The logical term operant and was used in the search of items to match keywords. The period of time analyzed was from 1996 to 2014. It was included peer-reviewed articles. Based on this syntax, there were found 50 articles. After reading their abstracts, there were selected 25 articles that addressed issues.

\subsection{Characterization}

Mucuna Pruriens is a leguminous tree originally from India, but also found in countries like Sri Lanka, Malaysia, Southeast Asia and in tropical regions such as Central and South America. Its use is mostly made by small low-income populations as a source alternative food [1]

Mucuna pruriens is a member of Fabaceae family, made up for about 650 genera and 2.000 species. MP has about ten synonyms and it is known as "velvet bean, lion bean, nescafe, cowage" and others [8]. In the composition of MP it is possible to find a large amount of proteins $(28.2 \%)$ and carbohydrates $(60.0 \%)$ while there is a small quantity of lipid $(2.7 \%)$. Furthermore, MP presents a good mineral composition.

The black color of the grain is related to the amount of $6.5 \%$ of varied phenolic compounds and tannins, presenting properties anticarcinogenic, in vitro antioxidant [9], anti-lipid peroxidation activities [10], hypoglycemic [3,11], hypolipidemic [5], diuretic and antimicrobial 
activity [4,12] and antigen against snake venom [13], therefore potentially beneficial to health [14].

However, there are anti-nutritional factors (AF) in their composition, such as tannins, phytic acid, enzyme inhibitors, trypsin, saponins, lectins, hemagglutinin activity $[1,7,15]$ and a high content of L-dopa, which makes it extremely toxic and unfit for human consumption. Common methods to eliminate anti-nutritional factors include cooking, roasting, drying, fermentation, alkaline solubilization, isoelectric precipitation [16] or ionizing radiation [17].

\subsection{Clinical Application}

Mucuna pruriens is used in its origin countries with several therapeutic goals, applying all parts of the plant: leaves, roots, hair, stems and grains, in the treatment of toothache, abdominal discomfort, colds and others [8]. MP is widely used in Ayurvedic medicine, Indian traditional treatment [15]. The most known use of MP is the treatment of Parkinson Disease. While synthetic L-dopa is the gold-standard drug used in the treatment of this disease, there is high quantity of L-dopa in MP and several studies have demonstrated reduction of the symptoms of Parkinson Disease with use of Mucuna pruriens [18,22]. It has also been demonstrated anti-inflammatory and anti-histaminic activities [3,20].

\subsection{Androgenic and Anabolic Activities}

In 2009 it was analyzed sexual behavior of normal mice treated with MP ethanolic extract, placebo or standard drug (sildenafil). MP extract seemed to increase ejaculation latency, mounting and intromission frequencies, and decreased mounting and intromission latencies, and postejaculatory and inter- intromission intervals. It was also observed increase in sexual organs weights and number and motility of sperm, confirming aphrodisiac property of MP extract [23].

Analyzing androgenic activity of MP it was observed increase in weights of testis, epididymis, seminal vesicle and prostate of mice that received supplementation of methanolic extract of MP for thirty days. Serum and testicular testosterone, protein content of the epididymis and testis and cholesterol significantly increased in treated group. These results are caused by androgen synthesis, demonstrated by increases of serum and testicular testosterone. These findings explain androgenic activity of $\mathrm{MP}$, relating it with the synthesis of androgenic hormones [6].

Testosterone-like activity of MP was analyzed in immature male rats. The animals were treated with aqueous or ethanolic extract of MP, testosterone or placebo during 14 days. Mucuna pruriens seeds increased serum total proteins, total and HDL-cholesterol without adverse effects in LDL-cholesterol, liver or kidney functions, confirming that MP extracts may have androgenic activity. These data explain the increase in anabolic activity and body weight of treated mice, since testosterone is an important anabolic hormone and leads to increase in lean body mass and consequently, increase in body weight [7].

Meanwhile, other group evaluated MP effect on infertile men semen profile. As results, they observed an increase in semen volume, concentration, motility and sperm count when compared to control group after treatment, based on administration of MP extract $(5 \mathrm{mg}$ ) during three months. Besides, lipid peroxides reduced $(1.85 \pm 0.11 \mathrm{nmol} \mathrm{MDA} / \mathrm{mL})$ and seminal lipid profile was hulled (total lipids, cholesterol, triglycerides and phospholipids). Vitamins $\mathrm{A}, \mathrm{C}$ and $\mathrm{E}$, which have antioxidant activity and stimulate synthesis of cells from immune system, increased in the group treated with MP [10].

Researchers have analyzed androgenic activity of MP and the findings are promising. However, there is no data relating treatment with MP, stimulus in anabolic hormones synthesis and muscle hypertrophy neither in animals nor in humans. This is an important aspect, since there is a growing use of herbal products with anabolic function, and it is also necessary to analyze the effectiveness of the new alternatives that promise to increase lean body mass.

\subsection{Practical Applications}

Aiming to achieve aesthetic results quickly, recreational athletes more and more have been using nutritional supplements. Studies show that the use of these products, which previously were intended to elite athletes, now are part of the day by day of the majority of active individuals, even those that practice physical training as a hobby [24].

There is not enough scientific evidence that confirm the real application of MP as a nutritional supplement that acts stimulating the lean body mass growth. Despite the verification that MP stimulates the synthesis of testosterone, an important anabolic hormone, there is no study relating the use of MP with physical training and increase in lean body mass [25].

No group of researchers evaluated MP activity in weight loss and performance. Several media propose that the possible increase in lean body mass caused by MP would lead to increase in metabolism and consequent weight loss, and they also attribute the improvement in performance to this gain in lean body mass. However, there is no scientific study that analyzes this theme and they also do not suggest any possibility, even speculative ones, of the use of MP to improve these aspects.

\section{Conflict of Interest}

The authors declare that they have no conflict of interest.

\section{References}

[1] Nwaoguikpe, R.N., Braide W., Ujowundu, C.O. "The effects of processing on the proximate and phytochemical compositions of Mucuna pruriens seeds (velvet beans)," Pak J Nutr, 10(10). 947-51. 2011

[2] Majekodunmi, S.O., Oyagbemi, A.A., Umukoro, S. et al. "Evaluation of the anti-diabetic properties of Mucuna pruriens seed extract," Asian Pac J Trop Med, 4(8). 632-36. Aug. 2011.

[3] Bala, V., Debnath, A., Shill, A.K. et al. "Anti-inflammatory, diuretic and antibacterial activities of aerial parts of Mucuna pruriens Linn," Int J Pharmacol, 7(4). 498-503. 2011.

[4] Eze, E.D., Mohammed, A., Musa, K.Y. et al. "Changes in lipid profile of rats administered with ethanolic leaf extract of Mucuna pruriens (Fabaceae)," Curr Res J Biol Sci, 4(2). 130-36.2012. 
[5] Shahaji, P.S., Parnu, S.A. "Estrogenic activity of Mucuna pruriens in swiss albino mice," IRJP, 2(4). 191-93. 2011.

[6] Muthu K., Krishnamoorthy, P. "Evaluation of androgenic activity of Mucuna pruriens in male rats," Afr J Biotechnol, 10(66). 2011.

[7] Ahmad, N., Zia-ur-rahman, Akhtar N. et al. "Testosterone like activity of ethanolic and aqueous extracts of Mucuna pruriens seeds and its effects on serum biochemical metabolites in immature male rats," Pak Vet J, 32(1). 60-64. 2012.

[8] Hammerton, J. "Mucuna pruriens: weed, invasive, or multi-use crop for the Bahamas?," College of the Bahamas Research Journal, 12. 4-15. 2003.

[9] Longhi, J.G., Perez, E., Lima, J.J. et al. "In vitro evaluation of Mucuna pruriens (L). DC. Antioxidant activity," Braz J Pharm Sci, 47(3). Jul-Set. 2011.

[10] Ahmad, M.K., Mahdi, A.A., Shukla, K.K. et al. "Effect of Mucuna pruriens on semen profile and biochemical parameters in seminal plasma of infertile men," Fertil Steril, 90(3). 627-35. 2008.

[11] Bhaskar, A., Vidhya, V.G., Ramya, M. "Hypoglycemic effect of Mucuna pruriens seed extract on normal and streptozotocindiabetic rats," Fitoterapia, 79(7-8). 539-43. Dec. 2008.

[12] Salau, A.O., Odeleye, O.M. "Antimicrobial activity of Mucuna pruriens on selected bacteria," Afr J Biotechnol, 6(18). 2091-2092. 2007.

[13] Tan, N.H., Fung, S.Y., Sim, S.M. et al. "The protective effect of Mucuna pruriens seeds against snake venom poisoning," J Ethnopharmacol, 123(2). 356-8. Jun. 2009.

[14] Bhat, R., Sridhar, K.R., Tomita-yokotani, K. "Effect of ionizing radiation on antinutritional features of velvet bean seeds (Mucuna pruriens)," Food Chem, 103(3). 860-866. 2007.

[15] Vadivel, V., Pugalenthi, M. "Studies on the incorporation of velvet bean (Mucuna pruriens var. utilis) as an alternative protein source in poultry feed and its effect on growth performance of broiler chickens," Trop Anim Health Prod, 42(7). 1367-76. Oct. 2010.

[16] "Anti-nutritional factors within feed ingredients," Food and Agriculture Organization of the United Nations. [on line]. Available: http://www.fao.org/fishery/affris/feed-resources-database/antinutritional-factors-within-feed-ingredients/en/. [Accesed Jan.2, 2017].

[17] Siddhuraji, P., Harinder, P.S.M., Becker, K. "The effect of ionising radiation on antinutritional factors and nutritional value of plant materials with reference to human and animal food," Food Chemistry, 78 (2).187-205. 2002.

[18] Mahajani, S.S., Doshi, V.J., Parikh, K.M. et al. "Bioavailability of L- dopa from HP-200 - a formulation of seed powder of Mucuna pruriens (Bak): a Pharmacokinetic and pharmacodynamic study," Phytoter Res, 10(3). 254-256. May. 1996.

[19] Hussai, G., Manyam, B.V. "Mucuna pruriens proves more effective than L-DOPA in Parkinson's disease animal model," Phytother Res, 11(6). 419-23.1997.

[20] Manyam, B.V., Dhanasekaran, N., Hare, T. "Neuroprotective effects of the antiparkinson drug Mucuna pruriens," Phytoter Res, 18(9). 706-12. Sep. 2004.

[21] Lieu, C.A., Kunselman, A.R., Manyam, B.V. et al. "A water extract of Mucuna pruriens provides long-term amelioration of parkinsonism with reduced risk for dyskinesias," Parkinsonism Rel Disord, 16(7). 458-65. Aug. 2010.

[22] Katzenschlager, R., Evans, A., Manson, A. et al. "Mucuna pruriens in Parkinson's disease: a doble blind clinical and pharmacological study," J Neurol Neurosurg Psychiatry, 75(12). 1672-77. 2004.

[23] Suresh, S., Prithiviraj, E., Prakash, S. "Dose- and time-dependent effects of ethanolic extract of Mucuna pruriens Linn. seed on sexual behavior of normal male rats," J Ethnopharmacol 122(3). 497-501. Apr.2009.

[24] Nieper, A. "Nutritional supplement practices in UK junior national track and field athletes," Br J Sports Med, 39(9). 645-49. 2005.

[25] Kreider, R.B., Wilborn, C.D., Taylor, L. et al. "ISSN exercise \& sport nutrition review: research \& recommendations," J Int Soc Sports Nutr, 7. 2-43. 2010. 